\title{
Investment Strategy in Brazil's Financial Market: Wide Possibilities of Choice Between Risk and Return
}

\author{
Ricardo Luis Chaves Feijó ${ }^{1}$ \\ ${ }^{1}$ School of Economics, Business Administration and Accounting at Ribeirão Preto. University of São Paulo, São \\ Paulo, Brazil \\ Correspondence: Ricardo Luis Chaves Feijó, Faculdade de Economia, Administração e Contabilidade, Av. dos \\ Bandeirantes, 3900, Ribeirão Preto, São Paulo, 14040-905, Brazil. Tel: 55-119-7120-0834. E-mail: \\ riccfeij@usp.br
}

Received: May 25, 2020

doi:10.5539/ijef.v12n8p40
Accepted: June 11, 2020

Online Published: June 28, 2020

URL: https://doi.org/10.5539/ijef.v12n8p40

\begin{abstract}
The research identifies general characteristics of the Brazilian financial market based on the formation of an efficient portfolio composed of imaginary assets whose performance follows the main indexes of financial return identified in this market. Therefore, exercises are performed with different risk and return strategies. We can imagine ten representative types of investors with different goals of return on financial investments and, consequently, different risk aversions. Investments are efficient in the Markowitz sense. It is understood that five very traditional financial investments are available in Brazil, four of them in securities and one in Itaú bank shares. A descriptive analysis of the performance of these assets over 23 years is offered, showing that, among other information, better returns are achieved by CDI indexed investments. The composition of the portfolios is calculated periodically, for the ten representative agents considered; also the quantity sold and purchased of each financial asset for each period and per agent, as well as the return of the individual portfolios, their cost and respective variances. In this hypothetical exercise, but done with real indexes, it is demonstrated by numerical simulation, in a program in Matlab, some interesting results. Among them, we accompanied the financial return on the portfolios and the monetary cost for each agent to maintain, over time, the same strategy.
\end{abstract}

Keywords: Brazilian financial market, efficient portfolios, risk management, numerical simulation

\section{Introduction and Literature Review}

Using a rich dataset with 23 years of daily observations, this essay offers several exercises with different risk and return strategies within the Brazilian financial market (Note 1). Therefore, ten representative types of investors with different targets for the return of financial investments and, consequently, different aversions to risk are imagined. In the individual assembling of financial asset portfolios, one imagines that such return targets are programmed according to the returns observed in the present period, so that the more ambitious of the agents, in terms of target return, desires a greater portfolio return as a percentage of the return of the maximum return asset in the period, among those observed, and the least ambitious of them expect the smallest portfolio return. The others ones are located in an intermediate range of desired returns. Investments are efficient in Markowitz's sense: they minimize portfolio variance for a given desired return level. The portfolio composition estimation is done by a Matlab program (Note 2).

On the basis of daily investments earnings data from 1995 to the present, weekly financial returns are estimated because we suppose one week as the period in which recombination occurs in the investment portfolio. The structure of taxes and the costs of intermediation of the process are disregarded. The composition of the portfolios is calculated periodically, for the ten representative agents considered, also the quantity sold and purchased of each financial asset for each period and per agent, as well as the return of the individual portfolios, their cost and respective variances.

In these hypothetical exercises, but done with real indexes, it is demonstrated by numerical simulation some expected results. In addition, the research provides estimates of efficient portfolios with short sale operations. These results, and details of the composition of the optimal portfolio, cannot be anticipated and are only obtained as outputs in the simulations. Besides that, it is also monitored the financial results on return of the portfolios and the monetary cost for each kind of agent to maintain, over time, the same particular strategy proposed. 
Efficient portfolio theory was originally proposed in Markowitz (1952). An intuitive introduction on these ideas is given by Copeland and Weston (1988). The optimal portfolio formation with real assets has been extensively examined. It is not proposed to completely review a well-known and documented literature. A good example of an interesting exercise in applying the theory with real data for emerging countries appears in Grujić (2016).

To this end, this essay is structured in five sections, including this one. The second section describes and justifies the particular choice of assets that will be considered in the simulation. The third section discusses the optimal portfolio determination technique and describes the behavior of selected Brazilian financial assets in the last 23 years. The fourth one presents the simulations of optimal portfolios composition and their results. At the end, a concluding section draws the main lessons from the exercise.

\section{The Choice of Financial Assets}

In this initial section, assets available in Brazil's financial market are selected. In fact, the possibility of financial investments in that country is quite complex and diversified. Securities with different indexation rules and different returns, as well as numerous investment and stock funds are available to the investor. In addition to banks, several brokerage firms and fund managers offer to their clients complex financial engineering for different investments, in a combination of risk and return capable of serving all types of clients. In this paper, however, we only choose four stylized types of bond investments and one in stock, that of Itaú bank, the most traded stock in the São Paulo Stock Exchange - Bovespa (11.31\% of the stock market index). Stock investments, in practice, make up only a small part of the value of the portfolio, even for the most risk-prone agent (in most periods, less than $1 \%$ of that value). This choice is explained by the fact that the stock market in Brazil is relatively small compared to the volume of money invested in securities.

Two of the assets selected belong to the category of Bank Deposit Certificates (CDB). They are investments in fixed income, which give the investor the option to know exactly how much their money will yield or choose to follow the interest rates of the market. They are securities issued by Brazilian banks as a way of raising funds with the objective of financing their activities. Such transactions function as an investor loan to financial institutions. In return for the loan, the bank returns the money repaid with interest. Given the amount applied and the recovery term, different options of CDBs exist, with specific returns and conditions.

In this paper, we work with CDBs' interest rates offered in the Central Bank of Brazil (BACEN) database, which reflect the average rates practiced in the market for this type of operation. The temporal structure of interest, according to the period of investment, the need for minimum values of deposits, brokerage costs and taxes are disregarded. Two types of investments in CDB are chosen: pre-fixed and post-fixed. In the first case, the yield is agreed at a predetermined rate. In the post-fixed CDB, the investor agrees with the bank some reference rate for the investment. Taking into consideration several factors, such as the economic scenario and the future prospects for the investment period, the investor chooses the type of post-fixed CDB. This is the safest type of CDB (Note $3)$.

Another type of financial investment considered in this essay responds by the name of CDI. The acronym stands for Interbank Deposit Certificates, which are securities issued by financial institutions in one-day, very short-term maturity loans between financial institutions. The average rate of one day's CDIs serves as the standard measure for the cost of money on all types of loans. Many financial investments in Brazil have the interest rate tied to CDI income, yielding a percentage of it. The security itself is traded exclusively among financial institutions. However, several financial products in Brazil are referenced to the DI rates that are obtained by the average interest rate that is negotiated by the banks in these interbank transactions with CDIs. These last rates are the highest in the market and will enter into our simulation as an investor investment choice (with 100\% return from it).

A fourth financial investment option in our model concerns savings account, which is the most popular investment in Brazil. It has daily liquidity and is paid monthly according to the determinations made by Brazilian legislation. They are offered to individuals and legal entities by public and private financial institutions. The financial investment is quite simple because it is exempt from income tax and administration fees. However, the return on investment is currently quite low. Finally, in the choice of financial assets that will make up the portfolio representative of the typical investments in the financial market in Brazil, we choose investments in shares of the Itaú financial institution. It is the largest Brazilian bank in annual profitability, having its shares traded in others stock exchanges around the world.

Adding a variable income asset to a basket of fixed income assets is not very usual in the literature on portfolio empirical exercises. However, we consider useful and interesting to include at least one variable income asset in our choice as a way to induce greater volatility in the portfolio under review. The four arbitrary types of bonds chosen for the simulations, in fact, represent assets remunerated by the main indexes of financial investments in 
Brazil, returns in estimates that disregard certain complications such as the incidence of brokerage costs and the structure of the tax burden. We have resolved to include only a variable income asset in our theoretical basket because, in fact, the stock market represents a very small fraction of the financial market in Brazil. The shares of the Itaú financial institution are chosen only because it is the largest bank in that country and the most traded shares in the São Paulo stock exchange. Otherwise there is nothing special about them, and could be replaced, in the simulation model, by another important share negotiated in Brazil

\section{Determination of the Optimal Portfolio}

In our simulation exercise, agents choose efficient portfolios. Given the actual series up to the period in question, the program finds the individual portfolio that minimizes risk at a given level of their desired return. As the market is efficient, let's look at the formal conditions for choosing the optimal portfolio. In light of Markowitz's well-known portfolio-building theory, based on mean and variance, let us see how formally an efficient portfolio is constructed. The one maximizes the expected return and minimizes risk. Consider a portfolio of $N$ assets $(N=1, \ldots, N)$. If the wealth, or money available, is 1 (for simplicity), the fraction of a unit of wealth invested in the asset $i$ is called $\theta_{i}(i=1, \ldots, N)$ (Note 4). The return rates of the $N$ assets in the period in question are expressed in the vector whose entries correspond to the observed data: $r=\left(r_{1}, \ldots, r_{N}\right)^{T}$. The covariance matrix of the returns of the assets is represented by $V=\left(\sigma_{i j}\right)$, where $\sigma_{i j}=\operatorname{cov}\left(r_{i}, r_{j}\right), i, j=1, \ldots, N$. (Note 5) The variances (and covariance) depend on the series of returns of each asset $r_{i}$ formed up to the period in comparison with that of another asset (or itself). The standard deviation of the asset is considered a risk measure. A certain combination of assets defines a specific portfolio. The expected return of this portfolio is given by $r_{p}=$ $r^{T} \theta$. In addition, we define a variance for the portfolio, understood as the variance of its return. Such variance can be expressed as $\sigma_{p}^{2}=\theta^{T} V \theta$. Portfolio risk is the standard deviation corresponding to this variance.

The quantities purchased $\left(\varphi^{h}\right)$ by agent $h$ in each period are such that, in the end, the individual will have an efficient portfolio $\theta^{*}$ in the interval in question. Let's see how the agent builds efficient portfolio. We look only at the returns desired by agent of the securities portfolio and at the covariance structure of the individual returns of each asset with each other. The problem of individual choice of the efficient portfolio can be formalized as follows: the agent seeks to achieve a certain level of desired return $r^{h *}$ with minimal risk. The corresponding portfolio is called the minimum variance portfolio, that is, it has the lowest risk. Formalizing:

$$
\min \frac{1}{2} \theta^{T} V \theta \text { subject to } 1^{T} \theta=1 \text { and } r^{T} \theta=r^{h *} \text {, for given target return } r^{h *}
$$

Let us now look at the general solution to the minimization problem in question for the case in which only assets with risk exist, and the presence of short sale is allowed. The most common occurrence is $1^{T} V^{-1} r \neq 0$. For this usual situation, the efficient portfolio-compatible solution is given by the expression:

in which,

$$
\theta^{*}=z_{1}+\mu z_{2}
$$

$$
z_{1}=\frac{1}{\Delta}\left(C V^{-1} 1-B V^{-1} r\right) \text { and } z_{2}=\frac{1}{\Delta}\left(A V^{-1} r-B V^{-1} 1\right)
$$

In these expressions, $\mu$ is the return desired by agent $h . A=1^{T} V^{-1} 1, B=1^{T} V^{-1} r, C=r^{T} V^{-1} r$ and $\Delta=A C-B^{2} . z_{1}$ and $z_{1}$ can be thought of as portfolios and therefore the efficient portfolio would be a combination of them (Note 5). Assuming that the chosen portfolios of assets for each agent are always efficient, the vector $\theta^{h *}$ of the asset allocations in the individual efficient portfolio is generated. Such a vector depends on the inputs of the matrix $V$ and the return vector $r$. The matrix $V$ of covariance of returns depends on the historical series of returns. In the first period examined, one starts from a historical series of weekly returns corresponding to 12 weeks or 3 months. Then, in the subsequent periods, the series will grow with additional data from the last week each. By adding a new period (the current one), the assets return series gain new entry and consequently determine a new matrix $V$. Altering the last entry in the time window of the returns, one can affect the calculated values of variances and covariance of assets.

In the period in question, the amount demanded (or supplied) of each asset is the one that, by construction, keeps the portfolio efficient. Thus, successive periods generate different individual portfolios that are, along them, conserved efficient given the agent's targeted return, specific to the step. Note that we still do not discriminate the investors with respect to the efficient portfolio vector $\theta^{h *}$ specific to each. At the same time, all portfolios must be efficient; and maintaining the common structure of $V$ and $r$ it would seem that there would be no way to distinguish agents in the process of choosing efficient portfolios. In the simulation model, however, the investor are different as to their desired return. In the portfolio risk minimization problem (given $\frac{1}{2} \theta^{T} V \theta$ ), each agent 
presents his portfolio desired return, expressed in the variable $r^{h *}$ that in the simulation is assigned by a certain criterion.

The criterion perfoms like this: The model works with the assumption that the targeted return is established by each investor in each period throughout the series. The desired return of the portfolio, for each agent, is done by observing the maximum return $\left(r_{m}\right)$ of the five assets considered at the end date of the period. It is imagined that the desired returns of the portfolio, for the 10 investors, compose the following vector: $\boldsymbol{r}^{*}=\left(r^{1 *}, r^{2 *}, r^{3 *}, r^{4 *}, r^{5 *}, r^{6 *}, r^{7 *}, r^{8 *}, r^{9 *}, r^{10 *}\right)=\left(\frac{r_{m}}{1,1}, \frac{r_{m}}{1,2}, \frac{r_{m}}{1,4}, \frac{r_{m}}{1,6}, \frac{r_{m}}{1,8}, \frac{r_{m}}{2}, \frac{r_{m}}{3}, \frac{r_{m}}{4}, \frac{r_{m}}{5}, \frac{r_{m}}{6}\right)$. It means, therefore, that the desired returns are distributed with reference to the observed maximum return $\left(r_{m}\right)$ of the best performing asset in the immediately preceding period, among the five observed assets. Table 1 expresses such targeted returns for each investor as a percentage of $r_{m}$.

Table 1. Returns of portfolios of 5 assets target by each investor $h\left(r^{h *}\right)$ as $\%$ of the maximum individual return of these assets $\left(r_{m t-1}\right)$ observed in the immediately previous period

\begin{tabular}{rcccccccccc}
\hline Investor & 1 & 2 & 3 & 4 & 5 & 6 & 7 & 8 & 9 & 10 \\
\hline Target return * & 90.91 & 83.33 & 71.43 & 62.50 & 55.56 & 50.00 & 33.33 & 25.00 & 20.00 & 16.67 \\
\hline
\end{tabular}

$* \% r_{m t-1}$ (maximum observed individual return).

Then, this vector of returns is used in the particular solution of the Markowitz problem for each investor. Using equations 2 and 3, the program determines the individual efficient portfolios of each by the end date of the period considered. In the formula $\theta^{*}=z_{1}+\mu z_{2}$, the choice of the optimal portfolio $\left(\theta^{*}\right)$ depends on $r^{h *}$. Then each agent $h$ is characterized by an own $r^{h *}$, and the individual efficient portfolio depends fundamentally on this (Note 6).

Let us see, then, how the quantities bought and sold are determined at each stage of the process: in the first period of analysis, or the 12th period of the series considered, given the composition of the individual efficient portfolios for the same period, the cost of the portfolio is the difference between expenses on the purchase of assets, of the five considered, less the sale (in the case, short sale) of possibly some of these same assets (negative values in the weights of the efficient portfolio in question). The calculation depends on the prices of the assets in the period in question. It starts with prices of one monetary unit in each of the securities considered, in the period immediately prior to the beginning of the whole series on January 2, 1995, 0.2322 monetary units for unit price of Itaú shares on this date. The sequence of prices from then on is estimated based on the respective series of returns (on Itaú shares do the opposite, returns are estimated based on quotations) (Note 7). In the first analysis period (12th period of the series, March 28, 1995) we have the asset price vector for the assets indexed by fixed-rate CDB, post-fixed CDB, CDI, savings account and Itaú shares as the vector (1.1590, $1.0579,1.1546,1.0864,0.2671)$, as well as the composition of the portfolios for each agent in the first analysis period, and the costs of the individual portfolios formed.

It is assumed that each agent has an income on that date that allows him to acquire the portfolio in question. At the very beginning of the process, the quantities bought or sold (short sale) of assets are determined by the efficient portfolio vector $\theta^{h *}$, specific to each agent. In it, the investor mounts his initial portfolio. From the second period, the efficient portfolio for each agent changes from $\theta_{t}^{h *}$ to $\theta_{t+1}^{h *}$. The quantity of assets bought and sold for each investor $h$ is defined at $t+1$ as simply the difference $\theta_{t+1}^{h *}-\theta_{t}^{h *}$, with positive entries representing purchased values $\left(\varphi_{i}^{h}\right)$ and negative entries relative to values sold $\left(\psi_{i}^{h}\right)$. The Matlab program details these procedures both in determining the efficient initial portfolio and in the buying and selling strategy of each asset in the period in question (Note 8).

\subsection{Behavior of the Financial Assets}

The five types of financial investment in Brazil, considered when assembling the portfolios of 10 investors, differ in price evolution, periodic returns and volatility. As seen, for simplicity it is considered that each unit of asset is bought at one real on 01/01/1995 and the subsequent prices of this imaginary unit evolve according to periodic returns. That is, we observe the real series of returns of asset $i\left(r_{i}\right)$ in the construction of the respective theoretical series of prices $p_{i}$ of financial investments. By the well-known formula:

$$
p_{i t+1}=p_{i t}\left(1+r_{i t+1}\right)
$$


Data on returns of these investments appears on the BACEN homepage. For pre-fixed return in CDB, the table 14 of the BACEN was used; the post-fixed CDB returns were extracted from table 18 on the same page. CDI returns came from table 12 at the same address, and the monthly returns of the savings account investments were extracted from the table 25. Based on these tables, a careful treatment of the data was made; the first one is to align the dates on which the returns were collected and to calculated all returns at weekly rates. For CDBs and CDI, we compared two methods of temporal conversion: the first is to accumulate the values of the days in five consecutive business days and reach the value of the period. Given the presence of holidays and weekends, the total term between the first and the last considered date was considered, adjusting to the rate taking into account the lapse of real time involved. The reason for this method is that some data were weekly, but others were for periods of 5,8 or 9 days. We then chose to standardize a constant interval for periodic rates by considering the mean rate of return on the average of five daily rates of five consecutive days, and projected the financially equivalent rate to this for 7 days. That is, the rates obtained are always for equal intervals of 7 days. They were called $r_{i s}$ (weekly rates equivalent to the average of the respective daily rates of five consecutive business days).

Figure 1 shows the evolution of the weekly rates of returns for the four financial investments in bonds considered in this essay in portfolio formation: post-fixed CDB, pre-fixed CDB, CDI and savings account. It should be noted that the highest weekly rates of return occur for CDI indexed assets, closely followed by pre-fixed CDB returns.

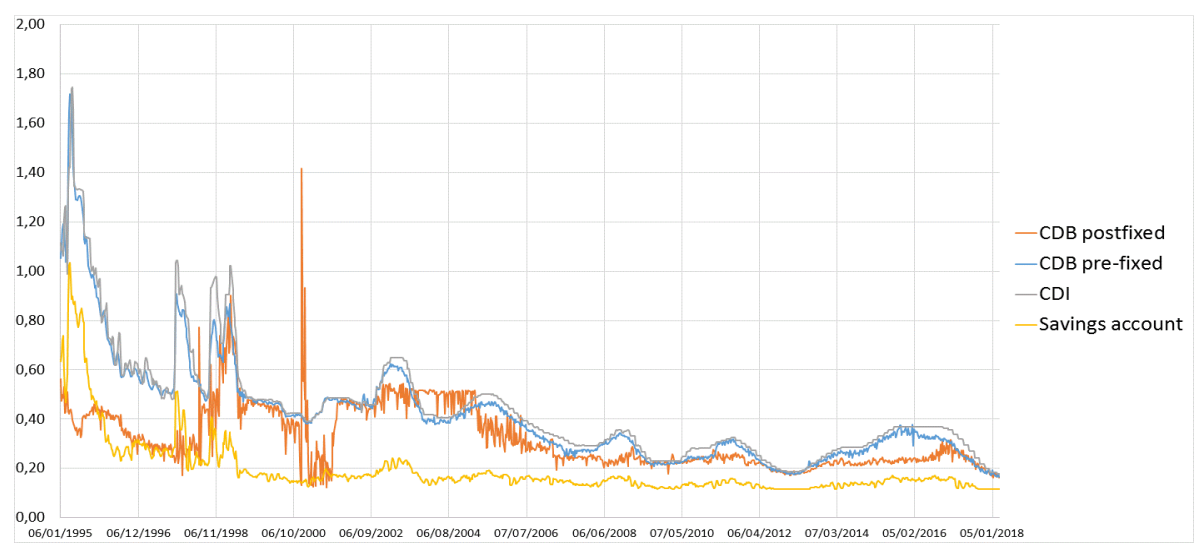

Figure 1. \% rate of weekly return of four financial investments in Brazil

Source: BACEN. Calculations of weekly equivalent rates made by the author. Date format: D/M/Y. Commas are used for decimal numbers.

Except for a few months in the second half of 2003 and the first half of the following year, post-fixed CDB rates of return have been behind the rates for the other type of CBD, or at most matched by them in a few months. Of course, the lower remunerations, except at the beginning of the series, up to mid-1998, are associated with the return in the savings accounts.

In the case of the investment in stocks, especially those of Itaú bank, the rates of return vary enormously from period to period, as they are variable income investment, the rates can become negative. Figure 2 shows the trajectory of the weekly rates of return on Itaú shares estimated based on the daily quotations of this share.

It is imagined that at the date before the start of the series, therefore on 01/01/1995, each unit of assets, involved in the formation of the portfolios considered, is acquired at one unit of Brazilian money called "real". Based on this, the weekly returns estimate the evolution of the prices of these assets. Figure 3 shows the evolution of hypothetical prices of post-fixed CDB assets, pre-fixed CDB, CDI and savings account. From January 1995 to the most recent date in 2018. As explained in the note at the foot of the Figure, the quotation of the Itaú shares at January $6^{\text {th }}, 1995$, in the amount of 0.2322 real, was converted to unit basis value to comparison with the prices of the other assets involved.

Note that in the period considered, a little more than 23 years, the prices that grew the most were Itaú shares, despite the strong fluctuations in the period. This trajectory corroborates the widely disseminated idea in Brazil that, in the long term, stocks seem to be the best kind of investment in the valuation of paper (Note 9). The trajectory of these shares, however, closely followed the prices evolution of the hypothetical asset indexed by the CDI rates. In fact, the CDIs are the fixed income securities with the best performance in the Brazilian economy. 
While Itaú shares appreciated from 1 to 217 reais, the prices of the hypothetical assets indexed by CDI increased from 1 to 172 reais. These numbers translate to a 21,600\% increase in Itaú's prices and a 17,100\% increase in the price of the hypothetical asset with returns indexed by CDI. Against a Brazilian inflation accumulated for the whole period of $506.4 \%$.

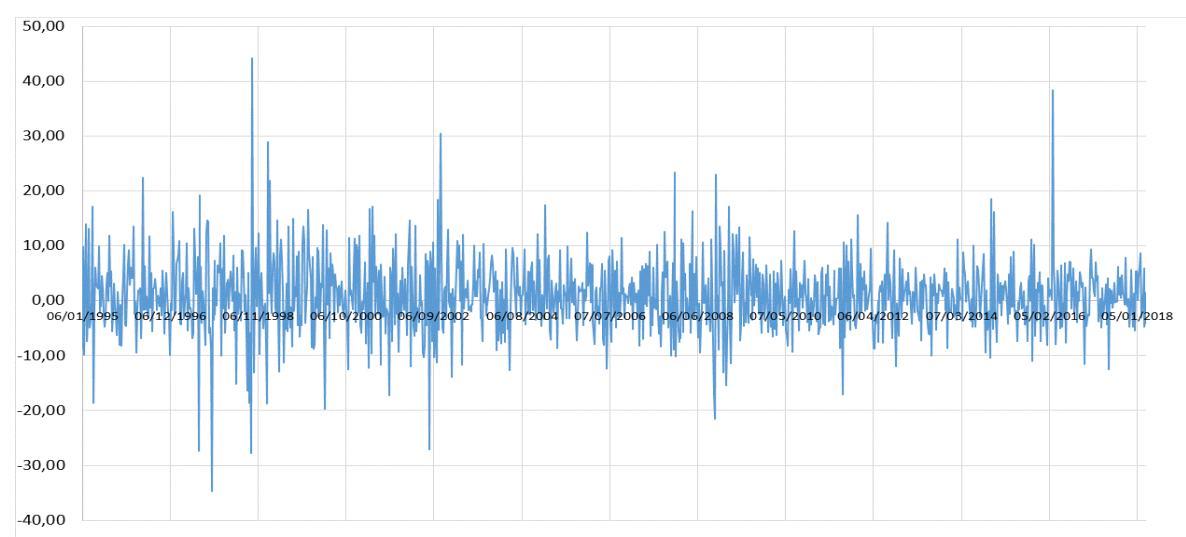

Figure $2 . \%$ rate of weekly return on Itau shares

Source: Author's calculations based on information from Economatica. Date format: D/M/Y. Commas are used for decimal numbers.

The performance of CDI investment deserves to be highlighted. In fact, Figure 3 shows that the high periodic returns of the investments indexed by this index cause the prices of these papers to grow much more than the accumulated inflation in the period. Not without reason, such index has been used as a criterion of good profitability in financial investments in Brazil.

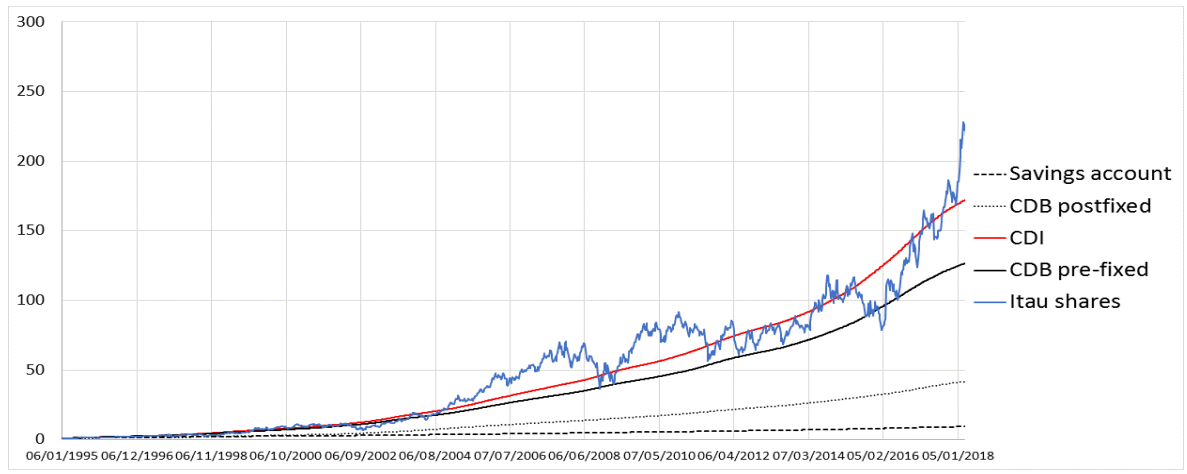

Figure 3. Price evolution of the five assets considered

Source: author's calculations based on BACEN information. Note: bond prices $=\mathrm{R} \$ 1$ ( $1 \mathrm{real})$ on January $1^{\text {st }}, 1995$. The price of the Itaú share on January $6^{\text {th }}, 1995$, in the amount of 0.2322 real, assumes the base value of 1 real for the purpose of comparison with the prices of other assets in the portfolio. Date format: D/M/Y.

CDB investments also experienced a good trajectory of growth in the prices of their respective bonds. In the period, the pre-fixed CDB valuation was much higher than in post-fixed CDB, as shown in the curves of the previous Figure. The accumulated growth in the theoretical price of these assets was 12,560\% in the first case, and $4,070 \%$ in the second. In the period under review, the theoretical prices of the asset indexed by the rates on the savings account investments grew more than the accumulated inflation in question, because the growth in the case was $832 \%$.

It is believed that the investments with the highest rate of return are related to a higher risk, which have, on average, a greater variance in the returns. The variance and covariance of the returns of the five assets in the portfolio constitute the inputs in the matrix $V$ of covariance of the returns of the assets $\left(V=\left(\sigma_{i j}\right)\right)$. In the Matlab program, the command "V $=\operatorname{cov}\left(\mathrm{X}^{\prime}\right)$ " generates the matrix $V$ by considering the whole range of the series up to the period in question (window of observation of variable size at each successive step). In the spreadsheets, however, we preliminarily consider the estimation of the standard deviations of the return series 
based on a fixed-size window of 12 entries, which is equivalent to the time interval of one quarter (Note 10). Figure 4 shows the evolution of the standard deviation of the returns, for fixed observation window, of the four fixed income assets involved in the construction of the portfolio.

It should be noted that, in fact, the standard deviations of the temporal returns of the asset indexed to CDI are higher than those of the other assets at the beginning of the series up to 1999. However, in many other years the standard deviation of the returns of the asset CDB are the largest. High yields with relative low risk (measured by their oscillations) actually make the CDI indexed securities highly desirable assets for the investor. It is not by chance that in Brazil the market with CDI indexed securities is immense. It should also be noted that the volatility of the indexed asset in fixed-rate $\mathrm{CDB}$ is generally lower than the corresponding post-fixed rate for most dates considered. As expected, the smaller fluctuations occur in the investments of lower return, the savings accounts.

It is not by chance that in Brazil the market with CDI indexed securities is immense (Note 11). It should also be noted that the volatility of the indexed asset in fixed-rate CDB is generally lower than the corresponding post-fixed rate for most dates considered. As expected, the smaller fluctuations occur in the investment of lower return, the savings accounts. While the return oscillations of fixed-income assets are within a range of standard deviations below 0.1 , from the year 2000 to the present, with insulated peaks from post-fixed CDB fluctuations that do not reach 0.4 , and fluctuation below 0.3 for all that year; in the case of Itaú shares, the variable income securities in question, there were strong fluctuations in returns, with typical values around 6 and peaks reaching up to 18 units. Indeed, in this type of investment returns fluctuate a lot, which is why they are very risky for short-term investment. Figure 5 shows the trajectory of the standard deviations of these stocks since 1995.

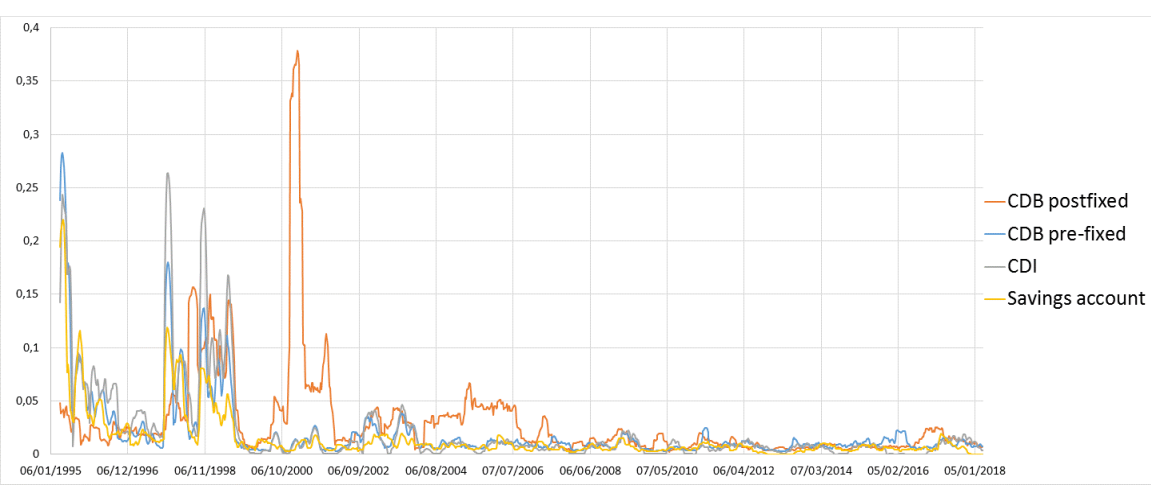

Figure 4. Standard deviation of five financial investments

Source: author's calculations based on BACEN information. Date format: D/M/Y. Commas are used for decimal numbers.

After this description of the behavior of Brazilian financial assets that will compose the investment portfolio under analysis, the next section offers simulations of composition of optimal portfolios, which will serve as a subsidy to the important analyzes that we intend to highlight in this research. It should be noted that these theoretical assets and their respective real indexes represent typical criteria for the remuneration of financial investments in Brazil and, therefore, are well representative of the local reality of this market.

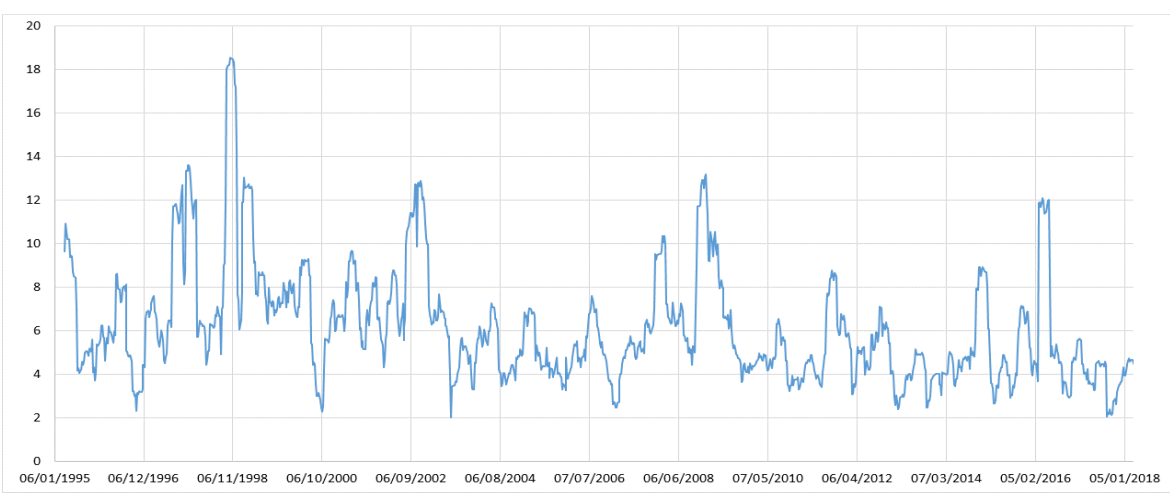

Figure 5. Standard deviation of Itaú shares

Source: author's calculations based on Economatica information. Date format: D/M/Y. 


\section{Optimum Portfolio Simulations}

Based on the developments offered in the previous sections of the paper, in this section we show and comment the results of the simulation done with the Matlab program. We saw that for each agent the program estimates the efficient portfolio composition that minimizes the variance of the portfolio for each of the 1,164 weekly periods considered in the simulation. The program generates, among other information, an Excel file which contains the weekly rates of return of the efficient portfolios of each period, broken down into the 10 types of investors considered, with an increasing degree of risk aversion, therefore with respective lower and lower target returns, as identified in Figure 6 for investor 1 to 3 and 7 to 10 (the three least and the four most risk averse ones).

It should be noted that investor portfolios that aim for higher return as a target actually have a higher weekly rate of return. These rates fluctuate taking into account that the desired rates of return vary over time because they are individually reprogrammed each period based on the observation of each of the results in terms of the actual returns of the assets in the immediately preceding period. Investors 1, 2, and 3 build portfolios that result in higher returns, as is their desire. Note that in the Figure below the returns are getting smaller until the average return of the asset portfolios to the investor 10 is reached.

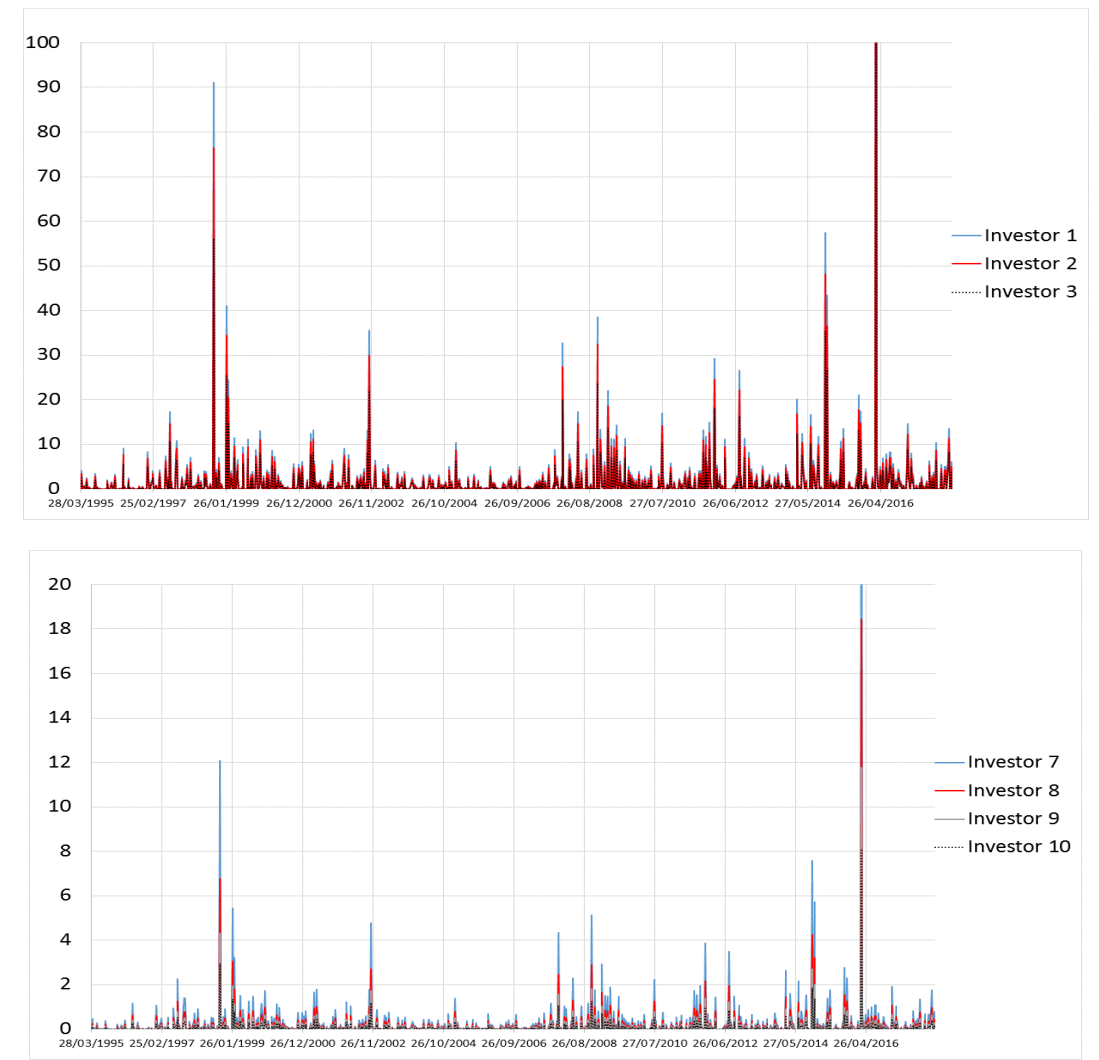

Figure $6 . \%$ rate of weekly return of individual portfolios with the same 5 assets for investors with different risk propensities (different target portfolio returns)

Source: BACEN, calculations made by the program in Matlab. Date format: D/M/Y.

The choice of portfolios with better performance by the first investors entails, in contrast, two orders of costs. First, the costs of the most profitable portfolios fluctuate more sharply. The investor with this type of portfolio can both gain a lot from the recomposition of each period and may have to bear a very high cost in order to maintain efficient portfolios in the light of the systematic proposal in this essay. Figure 7, for the same investors, shows that for the first three investors the cost of maintaining efficient portfolios fluctuates in the range of up to $\mathrm{R} \$ 4000$ per week, either as a gain or as an expense, with a single moment when this threshold was exceeded; however fluctuation is much smaller for the more modest investors (7 to 10) with costs of maintaining the strategy of weekly recomposition that rarely exceed one thousand reais.

Another cost of maintaining portfolios with higher returns, each period, refers to the higher risk of higher yield portfolios; risk measured by the fluctuations quantified in terms of variance or standard deviation of the return. 
Figure 8 shows the standard deviations of efficient portfolio returns measured on the basis of a quarter-size constant window that moves in order to measure the volatility at each point in the respective series of portfolio returns. It should be noted that the scale changes from one chart to another, clearly indicating that return oscillations are much smaller in asset portfolios in which lower recurring yields are desired.
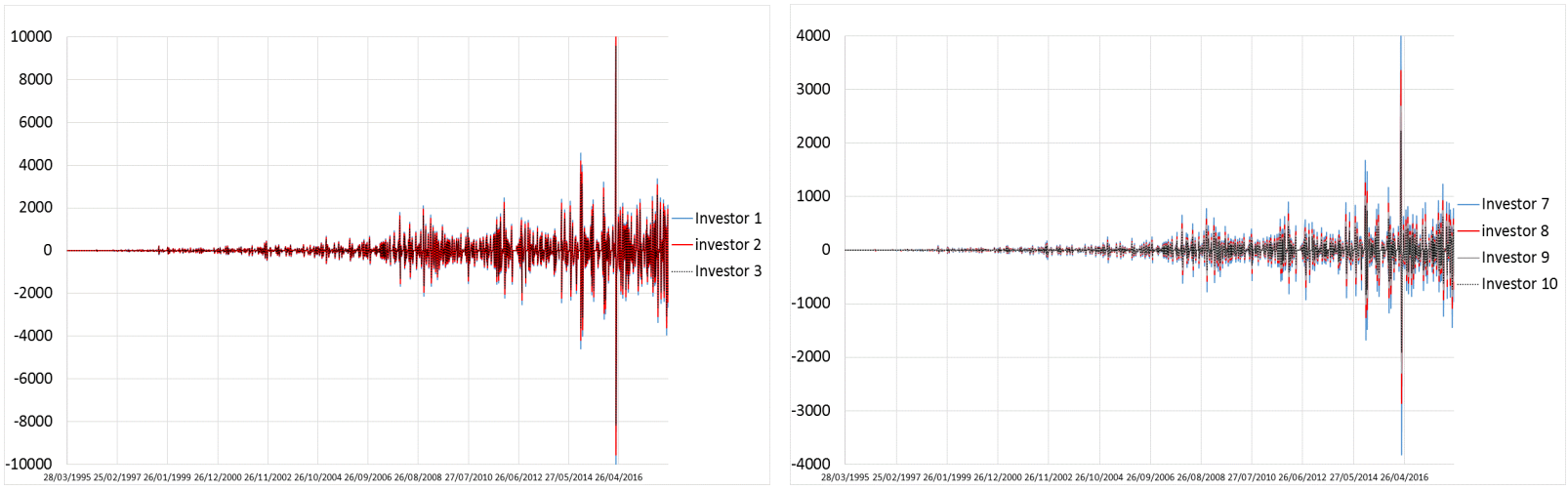

Figure 7. Portfolio cost (in real) for 7 investors in increasing order of risk aversion

Source: author's calculations. Calculations made by the program in Matlab. Date format: D/M/Y.

Figures 7 and 8 were done in Excel, but the Matlab program produces, as output, the worksheets from which they were generated. The user of the developed Matlab program navigates through command windows in which he/she inputs simulation parameters such as number of assets (up to five) and number of observations. As output data, the same window informs the average return of the portfolio for each agent. Then the user must inform the number of investor he/she wants to follow the evolution in the composition of the portfolio (1 to 10). The system then provides for that informed investor the evolution in the composition of the portfolios until the period 26 (Note 12). In the simulation, all portfolios in 1,164 observations are recorded in the respective output sheet of the program. In the exercise, the average return of the portfolio is repeated for the 10 investors under analysis. It is seen that the first investor has an average return in all these periods of 1.86 reais, the second in 1.56 reais and so on until it is recorded that the most risk averse investor assumes portfolios with only average return 6 cents of real.
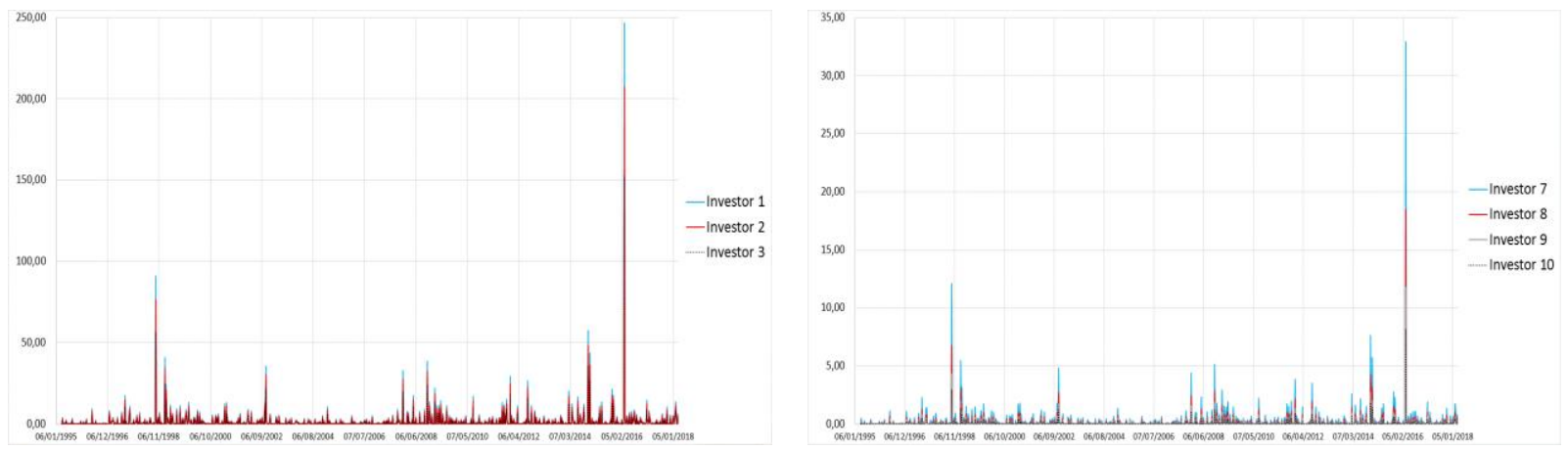

Figure 8. Standard deviations of portfolio returns from 7 investors in increasing order of risk aversion Source: Calculations made by the program in Matlab. Date format: D/M/Y. Commas are used for decimal numbers.

It is of great interest to follow the evolution of the composition of the portfolio over time. We are particularly interested in the importance measured by the relative weight of each asset in the construction of the portfolio, which each period meets the Markovian goal for a given target return. In order to further examine the issue, the output sheets of the compositions for the investors 1 and 10 are used in generating the Figures 9 and 10 shown below. The first Figure examines the evolution of the portfolio in the case of the investor 1 that seeks, each period, a portfolio with a return of more than $90 \%$ of the return of the maximum income asset in the immediately preceding period. He/she is the most demanding investor in return and more risk-lover among the 10 considered. 
This investor composes his/her portfolio primarily with pre-fixed CDBs, and a significant but less important share of the other type of CBD. CDI-indexed securities are used more in short-sale operations; they appear with slightly negative weight in the portfolio. The indexed asset in savings account remuneration is heavily used in short operations. Itaú's shares in the composition of the portfolios were practically not used.

Note that the weights are high because short operations are allowed, but of course all portfolios are normalized in weights that add up to 1 . The participation of the prefixed CDBs is generally below 40 , and that of the CDBs post fixed below 20. The CDI appears in short operations with weights of less than 10 . The share of savings account in operations of this type is much higher.

Looking at a more risk-averse investor, let us examine at how the evolution of the portfolio changes in the case of the investor 10 (Figure 10), the most prudent of them, which requires less return of the portfolios, is examined. This investor, on average, compose his portfolio with the least salient weights of $0.61,0.86,-0.16,-0.33$, and -0.0001 for assets indexed by pre-fixed CDB, post-fixed CDB, CDI, savings account and Itaú shares, respectively. There are fewer short trades, less "leveraged" operations, and on this case, curiously, the share of post-fixed CDBs in the portfolio is higher than the fixed-rate ones.

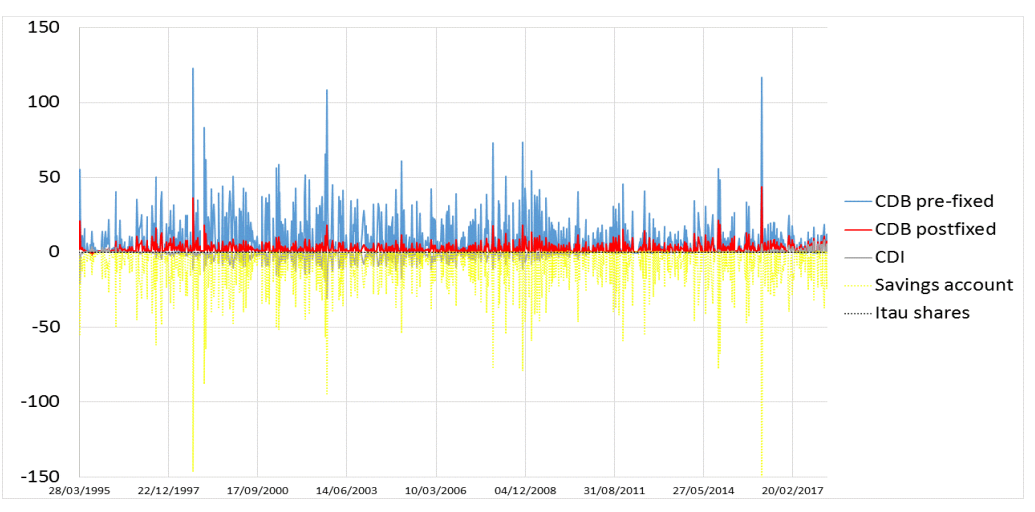

Figure 9. Evolution of the portfolio for the investor 1. Weights represented on the vertical axis

Source: BACEN. Calculations made by the program in Matlab. Date format: D/M/Y.

In any case, for 10 types of investors, we note the almost negligible participation of the stocks in the composition of the portfolio by the imagined system. Looking at the Figures 3, 4 and 5 one can conjecture an explanation of the reason for the low participation of these shares in the construction of efficient portfolios. The first of these Figures shows that although Itaú shares prices have grown in these 23 years more than the price evolution of all the considered fixed income bonds, they did not grow much more than the prices of the assets indexed by CDI. In fact, the CDI price curve looks like the adjustment curve of the share price trajectories in question. On the other hand, it can be seen in Figures 4 and 5 that fluctuations in stock prices are much larger than the fluctuations of those other assets. That is, the inclusion of these stocks in the portfolio contributes less to the increase of the return and much more to the growth of the risk. For this reason, among other reasons that could be sown, in the efficient portfolios Itaú shares are almost not present.

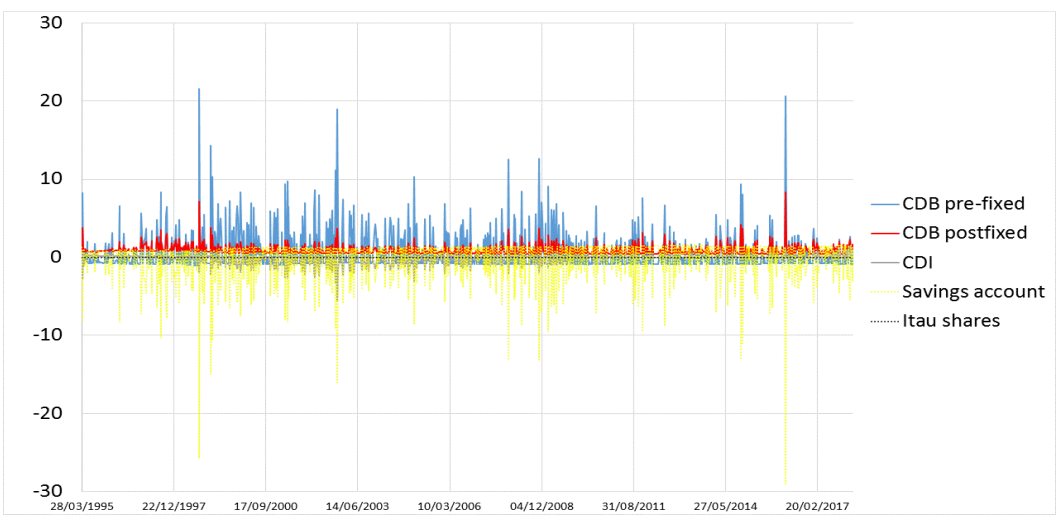

Figure 10. Evolution of the portfolio for the investor 10. Weights represented on the vertical axis 
Another simulation exercise could be carried out in the formation of efficient portfolios without the hypothesis of short sale, only with positive weights in the participation of the assets. It would be interesting to look at this alternative model; however, in finance most of the portfolio models admit short positions. In addition, the general solution to the problem of risk minimization in portfolios, presented in equations 3 and 4 , only applies to the case where short sale is allowed. Other theoretical developments would be needed to treat the other case, which were not considered in this paper.

\section{Conclusion}

The fees involved in the remuneration of CDBs, CDIs, and savings accounts are the most important in the fixed income market, although professional management funds are offered to surpass these basic rates of the financial market in Brazil. The complex structure of the evaluations, with minimum contributions and incidence of taxes and brokerage costs, makes the reality much more complex than the simulation model developed in this essay. However, here we have tried to highlight the broad possibilities of choice between risk and return, in fixed and variable income securities offered by the Brazilian financial market (Note 13).

The investment strategy based on the formation of efficient portfolios deals with a basic expedient in the microeconomic theory of finance. This type of exercise has been widely applied in financial market simulation, and it has been sought here to provide a simple but precise and rigorous technique that has been able to handle a vast mass of data with thousands of information covering a long period of more than 23 years.

The paper presents a detailed description of the performance of different financial investments taking into account the main financial index in Brazil. For example, the good performance of the investment that pay the CDI index is evident. The paper also shows how easily one can develop and monitor theoretical portfolios for the good use of Matlab programming and the use of appropriate routines rigorously supported by theoretical concepts well accepted in the literature. In fact, other additional hypotheses could significantly improve the relevance of the study, e.g. include other types of assets with other possible indexes, and perhaps another variable income asset to compose with Itaú shares. The tax structure in financial investments and maturity yields of securities (i.e., yields for different redemption periods) would certainly enrich the study and make it applicable. However, the scope of this study runs away from a more immediate application.

Given this, it is believed that this type of simulation is fruitful because it offers ample possibility of extensions. Of these, portfolio forecasting exercises stand out. In fact, by analyzing the pattern of portfolio returns we can see the presence of strong volatility in the series. The underlying generating process could be estimated by employing techniques with Garch processes. So, the model would act not only in predicting the returns of particular assets but also in forecasting the returns of the portfolios, with evident benefits in the orientation of the investor in the financial market. Theoretical portfolio generation models should be supplemented with generative process identification models and forecast models. This was only one stage of a research that is intended to be broad and in which we have been involved for some time.

\section{References}

BACEN. (n. d.). SGS - Sistema Gerenciador de Séries Temporais - v2.1, Módulo público, Mercados financeiros e de capitais, Aplicações financeiras: cadernetas de poupanças, depósitos a prazo ('SGS - Time Series Management System - v2.1, Public module, Financial and capital markets, Financial Investments: savings account, term deposits'). Retrieved April 26, 2018 from https://www3.bcb.gov.br/sgspub/localizarseries/localizarSeries.do?method=prepararTelaLocalizarSeries.

Copeland, T. E., \& Weston, J. F. (1988). Financial Theory and Corporate Policy (3rd ed.). New York: Addison Wesley Publishing Company.

Dupacová, J., Hurt, J., \& Stepán, J. (2003). Stochastic modeling in Economics and Finance. Dordrecht, The Netherlands: Kluwer Academic Publishers.

Economatica (software). Ferramentas básicas. Screening. Ações, relatório básico ("Basic tools. Screening. Stocks, basic report"). ItauUnibanco.

Grujić, M. (2016). Application of the modern porffolio theory in diversification of the debt securities portfolio in emerging markets. Proceedings of the Faculty of Economics in East Sarajevo, 3, 67-80. https://doi.org/10.7251/ZREFIS1613067G

Mais Retorno Broker. (n. d.). Retrieved April 26, 2018 from https://maisretorno.com

Markowitz, H. (1952). Portfolio selection. The Journal of Finance, 7(1), 77-91. https://doi.org/10.1111/j.1540-6261.1952.tb01525.x 
Siegel, J. J. (1998). Stocks For The Long Run - The definitive guide to financial market returns and long-term investment strategies (2nd ed.). New York: McGraw-Hill.

\section{Notes}

Note 1. The data were extracted from the Economatica database, specific to the areas of Economics, Administration, Accounting, among others. Economatica is a Brazilian company, leader in the development of systems for investment analysis. Since its founding in 1986, the company has maintained $100 \%$ of its focus on collecting and managing highly reliable databases as well as the ongoing development of high performance analysis tools. It is currently following the capital markets of major economies in Latin America and the United States.

Note 2. Matlab program that generates efficient portfolios and calculates costs and returns of this portfolio for each period, as well as their variance, is available to the interested reader. The request must be made by e-mail (riccfeij@usp.br).

Note 3. There are also hybrid bonds of CDBs that are nothing more than the union of the pre and postfix. In this modality, part of the pre-fixed profitability is received and the other part is post-fixed. In the paper, this type of investment is not considered.

Note 4. Note that $\theta_{i}<0$ also has economic significance. It translates the situation of short sale or even a situation of lends indexed to asset.

Note 5. See Dupacová et al. (2003). pp. 79-91.

Note 6. Note that we use this criterion because we did not assume, in this investigation, a utility function for agents and we are not concerned with monetarily measuring the degree of risk aversion, such as an ARA or RRA measures. The abstract criterion of discriminating agents by the "desired rate of return based on the maximum rate of return observed in the immediately preceding period" is just a particular way of discriminating agents regarding risk behavior.

Note 7. In fact, as we have accurate information on the prices of shares traded, real prices are used in this case, not price indexes estimated based on the returns as in the case of the bonds. The prices of these shares are used for a simple estimate of the net return of the investment because dividends and other forms of financial gains from shares are disregarded in addition to the price variation.

Note 8 . The reader who is interested in the code may request the author by e-mail.

Note 9. About a broad study of the long-term performance of equity investments, see Siegel (1998).

Note 10. Command "DESVPAD.A" of Excel program.

Note 11. About R $\$ 580$ million of CDIs are traded in one year. Only the stock of debentures that remunerates investments according to the DI rate is almost 700 billion reais. More than 8,500 investment funds in Brazil have the objective of exceeding the CDI. This represents half of all active funds in the country. In 2013, the total investments that were pegged to CDI were almost 1.7 trillion reais, representing $89 \%$ of the total stock of securities proved in Brazil. Source: Mais Retorno Broker.

Note 12. The reader who is interested in the Matlab program that generates the command window with program prompts may request the author by e-mail

Note 13. This essay focuses on the return and risk analysis (measured by asset and portfolio variance). However, other aspects of the Brazilian financial market could be explored. One of them has already been mentioned, which is the low participation of assets of varied income, another aspect is the complex tax structure that affects the financial investments, the high cost of brokerage and the strong participation of the public sector in the issuance of securities. However, the analysis of these aspects is beyond the scope of this study, which is concerned with the more general and stylized facts of this market.

\section{Copyrights}

Copyright for this article is retained by the author(s), with first publication rights granted to the journal.

This is an open-access article distributed under the terms and conditions of the Creative Commons Attribution license (http://creativecommons.org/licenses/by/4.0/). 